\title{
The effect of heparin prescription before primary PCI on long-term and short-term clinical and para clinical results and the mortality of patients with acute coronary syndrome
}

\author{
Bijan Zamani, Asghar Abdollahi*, Afrooz Mardi
}

Department of Medicine, Ardabil University of Medical Science, Ardabil, Iran

Received: 28 January 2018 Accepted: 06 March 2018

*Correspondence to:

Dr. Asghar Abdollahi, Email: asghar.abdollahi2015@ gmail.com

Copyright: (C) the author(s), publisher and licensee Medip Academy. This is an openaccess article distributed under the terms of the Creative Commons Attribution NonCommercial License, which permits unrestricted noncommercial use, distribution, and reproduction in any medium, provided the original work is properly cited.

\begin{abstract}
Background: Primary PCI (PPCI) is the main reperfusion treatment for STsegment elevation myocardial infarction (STEMI). Anticoagulation therapy should be administered in patients undergoing PCI in order to limit the ischemic complications. In this study, we evaluated the effect of bolus unfractionated heparin (UFH) before PPCI on clinical outcome of patients with STEMI.

Methods: In this randomized clinical trial, 196 patients $(72.4 \%$ male with mean age of $63.02 \pm 13.37$ years) with STEMI undergoing PPCI were randomly assigned to receive bolus UFH 60-90 U/kg in emergency room (case group) or during PCI (control group). Clinical outcomes, 30 day mortality, hematoma, left ventricle function improvement during follow-up were compared between groups.

Results: In both groups there was good flow in the involved coronary artery after PCI. Case group compared to control group had significantly more cases with improved LVEF (28.1\% vs. 9.7\%, p=0.005). Also, case group compared to control group had more hematoma $(3.1 \%$ vs. $0 \%, \mathrm{p}=0.24)$ and higher mortality rate $(6 \%$ vs. $4.2 \%, \mathrm{p}=0.56)$ which had no significant difference between groups. Conclusions: PPCI in patients with STEMI accompanies with acceptable coronary flow irrespective of receiving bolus heparin. Receiving bolus heparin in these patients may have improved left ventricle function by increasing the rate of reflow. However, using bolus heparin did not accompany with increased rate of bleeding and had no effect on 30 day mortality rate.
\end{abstract}

Keywords: Clinical outcome, Heparin, Primary PCI, ST elevated Myocardial infarction

\section{INTRODUCTION}

Coronary artery disease (CAD) is the main cause of death, morbidity and disability in the world and their prevalence is highly increasing in developing countries. In CAD patients, acute coronary syndrome (ACS) has the most importance because of the high possibility of unpleasant cardiovascular events during follow-up was more in these patients. In 2008, 7.3 million (12.8\%) out of 57 million deaths was because of myocardial infraction. In the United States, almost 650 thousand patients get new acute myocardial infraction (AMI) per year. The rate of early death (30 days) with AMI is about $30 \%$ and more than half of these cases occur before reaching to the hospital. ${ }^{1,2}$ During the last two decades, the rate of the death of coronary disease is decreasing in developed countries, whereas it is increasing in developing countries which is mostly because of long lifetime, urbanization and lifestyle changes. $^{3}$

In the United States, the adjusted rate of death based age due to coronary disease has been declined to two third in four last decades which is the reflection of better diagnosis and reduce risk factors and also improvement of faster 
treatments and interventions for control of heart diseases. ACS needs a precise diagnosis and early hospitalization and prognosis of patients is directly associated with on time conducting vascularization, so non diagnosis or delayed diagnosis can have disaster clinical effects. Triage and management of the patients with chest pain has to be done appropriately. In addition, early diagnosis of ACS decreases the rate of side effects and the risk of long-term relapse and finally leads to its low economic loads on health system. In general, ACS includes unstable angina (UA), myocardial infraction with and without increasing ST part (NSTEMI). ${ }^{4}$ Among these cases, STEMI requires more urgent intervention and early reperfusion to restore myocardial function and prevention of ischemia and myocardial necrosis. Proper reperfusion is done by thrombolysis or primary PCI which can decrease the size of infract, protect the left ventricle and improve the longterm and short-term consequences of disease. ${ }^{5,6}$ Doing primary PCI is the strategy of selective reperfusion in STEMI patients and when it is done urgently and in first hours of MI, it is effective in re-establishment of blood flow and this method is useful for patients with contraindication of fibrinolytic therapy. It seems that this method is more effective than fibrinolysis in bypassing clogged arteries and when it is done by experienced stuff and in specialized centers, it will be with long-term and short-term results. In fact, the rate of intra hospital death of STEMI has significantly decreased by improving reperfusion method during these years and currently it is between $6 \%$ to $14 \% .^{7,8}$ Coagulation treatment should be done in patients under PCI to limit the side effects of ischemia. However, this treatment can increase the risk of bleeding which is strongly associated with intra hospital and late disasters. Despite of the known limitations for heparin, still the unfractionated heparin is the most common used anticoagulant during PCI. ${ }^{9}$ The primary aim of treatment with anticoagulant drugs, is bypassing and protecting the infracted artery with strategies of reperfusion. The secondary aim includes decreasing thrombosis creation and then decreasing the possibility of wall coagulation (coagulation in heart) or deep vein thrombosis (that each can cause pulmonary embolism). Existing information demonstrates that when heparin is added to aspirin or nonspecific thrombolytic drug for fibrin like streptokinase, the rate of death in patients decreased more. It seems that intravenous injection of heparin with aspirin and almost specific fibrinolytic drugs for fibrin leads thrombolysis to facilitate and infracted vein remains bypassed. ${ }^{2}$ The aim of this study is to determine the effect of heparin prescription before primary PCI on long-term and short-term clinical and para clinical results and mortality of patients with acute coronary syndrome.

\section{METHODS}

This is a randomized clinical trial that has been done on 196 patients with ACS which candidate to PCI surgery. The exclusion criteria included not receiving thrombotic medicine during past seven days, pregnancy, active bleeding, thrombocytopenia history with heparin, receiving heparin before hospitalization and thrombocytopenic patients. Patients randomly divided into two groups: intervention group (bolus 60-90u/ $\mathrm{kg}$ heparin UFH in emergency) and control group (bolus 60-90u/kg heparin as hospital routine and during PCI).

Clinical and para clinical results included: local side effects of angiography during hospitalization, coronal EF during hospitalization and 45 days after that, the rate of TIMI FLOW after operation and titer of coronal enzymes at first 24 hours and mortality after one month was recorded by a check list and compared in two groups. The patients signed a written consent for participating in study. Data were analyzed using statistical methods in SPSS.17. The $\mathrm{P}<0.05$ was considered meaningful.

\section{RESULTS}

The average age of patients was $63.02 \pm 13.4$ and age range was between $35-91.142$ patients were male $(72.4 \%)$ and 54 patients $(17.6 \%)$ were female. The mean age of patients in case group was $63.02 \pm 14.50$ and in control group was $63.02 \pm 11.91$. The average of Troponin in case group with $35.9 \pm 19.2$ significantly lower than control group with $39.1 \pm 17.03$. Increasing rate of second CTNI toward the basic (more than 5 units) in case group was $83 \%$ and in control group was $90.5 \%$ and the difference wasn't statistically meaningful. During hospitalization and 45 days after PCI, most of patients had hospital LVEF 40$50 \%$ and the difference between two groups was statistically meaningful (Figure 1 and Figure 2).

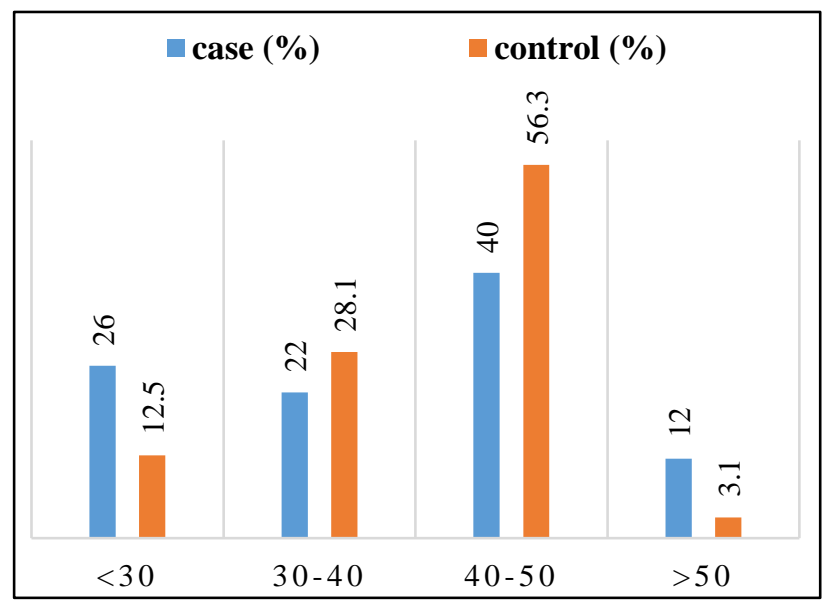

Figure 1: LVEF levels of patients in two groups.

The case group meaningfully had better rate of LVEF than control group during follow-up (Figure 3). TIMI FLOW before PPCI was grade $0-1$ in $91.6 \%$ of control group and $99 \%$ of case group (Figure 4 ).

After conducting PPCI, TIMI flow improve significantly in both groups so that in $89 \%$ of case group and $96.8 \%$ control group, TIMI was in grade 3 . All of the hematoma occurred in case group and the difference between two groups was not meaningful. 


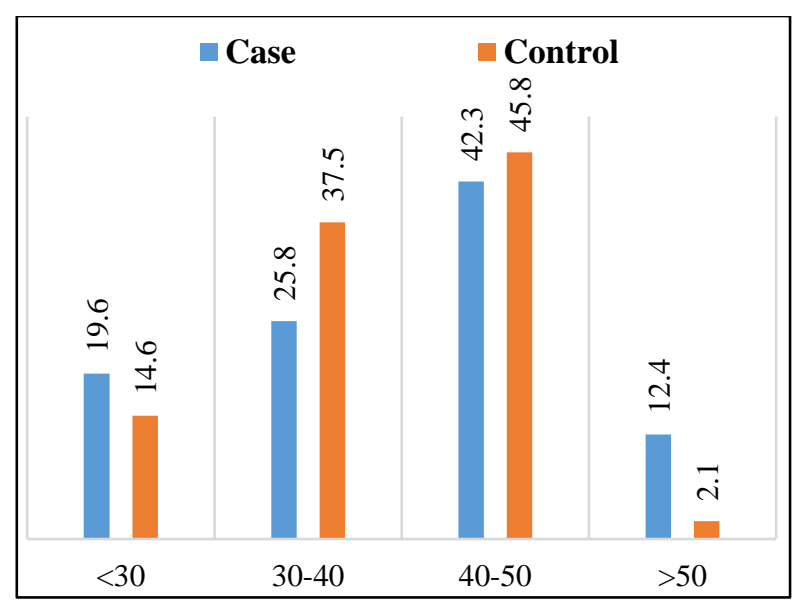

Figure 2: LVEF levels of patients 45 days after PPCI in two groups.

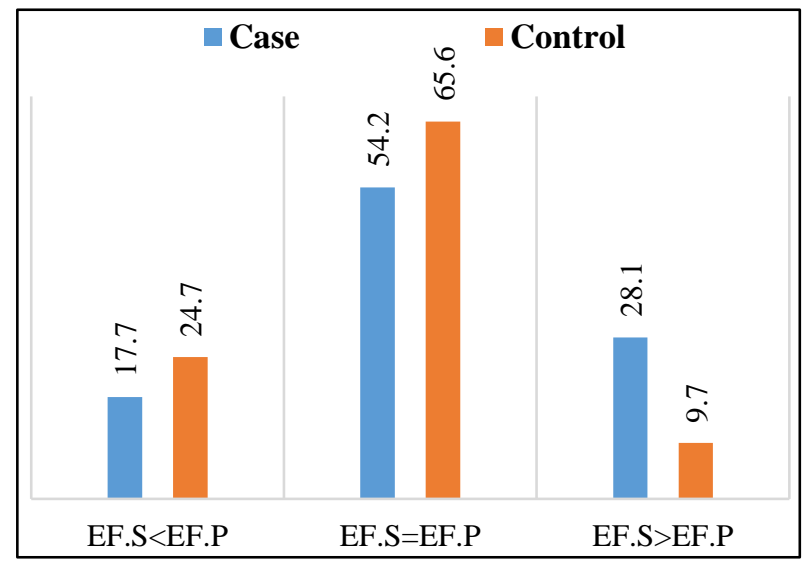

Figure 3: LVEF levels changes in patients compare to before amount in two groups.

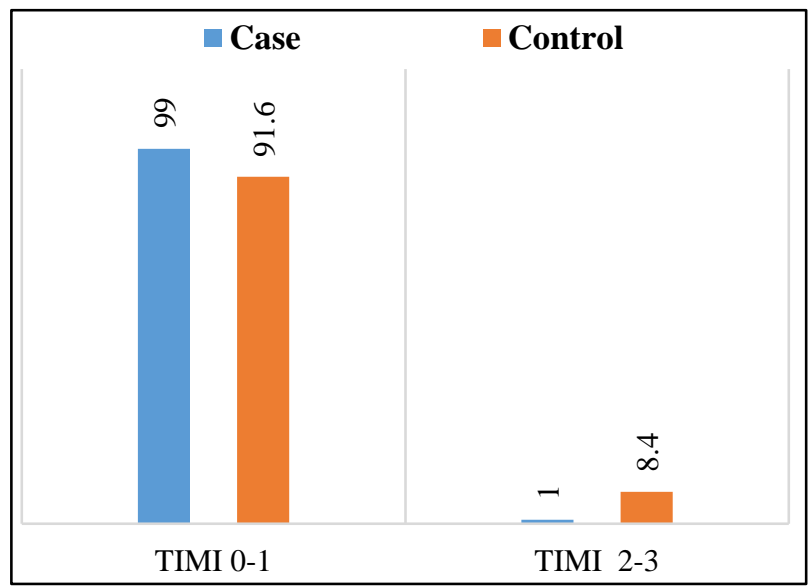

Figure 4: Frequency of TIMI flow before PPCI in two groups.

In present study, in $10(5.1 \%)$ of patients death cases was observed that $60 \%$ of them from case group and $40 \%$ of control group and the difference between two groups wasn't meaningful. 91 patients $(47.7 \%)$ with one coronary artery and 104 patients $(53.3 \%)$ with $2-3$ coronary arteries.
The frequency of mortality in cases with 2-3 VD was more than on artery but there was no meaningful difference between two groups. The patients with an artery had better primary LVEF than the patients with 2-3 VD (Figure 5).

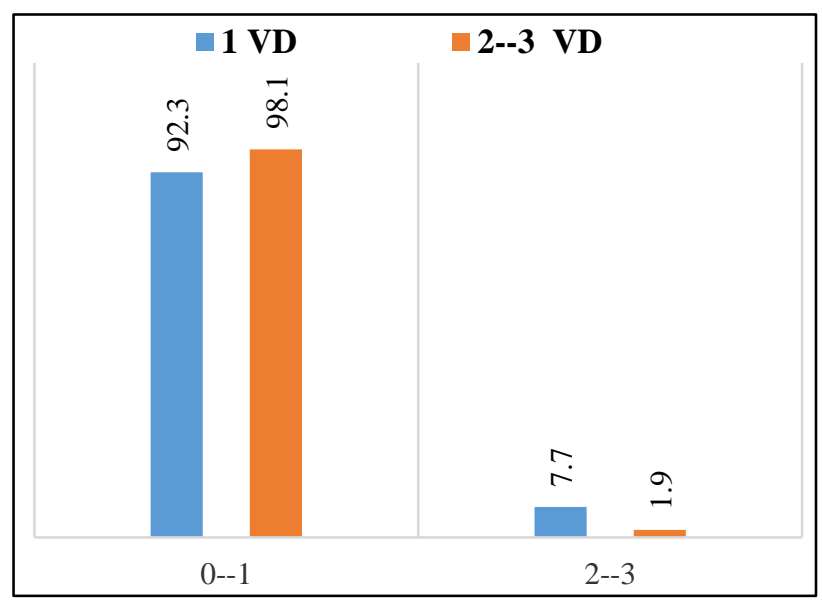

Figure 5: TIMI flow before PPCI by VD.

\section{DISCUSSION}

In this study 196 patient $(72.4 \%$ male and $27.6 \%$ female with the age average of $63.02 \pm 13.4$ years old) were evaluated. There wasn't significant difference between control and case groups in term of variables such as age, sex and the maximum CTnI. Miyachi et al, show in their paper that STEMI patients had the average age of 67 years old and majority was male $(75.5 \%)$. Male and upper age have been considered as risk factors for unpleasant consequences in STEMI. ${ }^{10}$ Similarly, it was observed in Cho et al. study that patient undergoing PPCI had the average age was 65 years old and mostly were male. ${ }^{11}$ It was observed in this study that following the treatment of patients generally LVEF have increasing and the cases with LVEF <30\% decreased after PCI during 45-day pursuing and the cases with LVEF $>50 \%$ increased. During comparison of hospital LVEF and during pursuing between two groups observed that LVEF below $30 \%$ and above $50 \%$ in case group is so much more than control group and $30-50 \%$ were more in control group. While the improvement of LVEF in case group was obviously more than control group.

Ottervanger et al, express that without PCI and angioplasty, the function of left ventricle and LVEF significantly improved after treatment. ${ }^{12}$ Also, Stolfo et al, observed during study that LVEF didn't improved following STEMI and PPCI in $28 \%$ of patients. These patients had lower LVEF during hospitalization and less improvement in LVEF during follow up. ${ }^{13}$ It was observed in Zijlstra et al, study that the patients receiving pre hospital heparin obviously had higher LVEF comparing other groups. ${ }^{14}$ Verheugt et al, observed that early treatment of patients with high dose of heparin be with complete coronary reperfusion at considerable amount of 
patients with AMI especially in patients who are treated below two hours, were associated. ${ }^{15}$

In this study, it is observed that 0-1 TIMI flow before intervention obviously in case group was more than control group (99\% versus $91.6 \%$ ) but after intervention there was no significant difference between two groups (3\% versus $1.1 \%$ ). This expresses that the influence of primary PCI in treatment of STEMI patients and improvement of their clinical situation while heparin injection before PCI doesn't effect on the treatment. Zijlstra et al, observed that TIMI score in damaged artery in heparin group was higher than other group which be with higher angioplasty success. ${ }^{14}$ Chung et al, investigated that the evaluation of early prescription of heparin in emergency on patency of coronary artery and its clinical consequences in STEMI patients, observed that TIMI was higher in 2,3 scores in heparin-receiving groups. In fact, this study expresses that in STEMI patients, early heparin treatment in emergency leads to improvement coronary patency. ${ }^{16}$

It is observed in this study that in case group in comparison to control group the rate of hematoma was higher $(3.1 \%$ versus zero \%) but not meaningful. The incidence rate of hematoma in different studies has been reported for different heparin receivers. In Stone et al. study, in heparin receiving patients, the major bleeding is occurred in $8.3 \%$ which was more than our study results. Also in Bonello et al. study the incidence rate of Hematoma in heparin group was more than B vali Rodin group (6.7\% versus $3.4 \%) .{ }^{17,18}$

In this study, the case group had more 30 day death in comparison to control group but difference was not statistically meaningful (6\% versus $4.2 \%$ ) and in fact it can be claimed that using heparin with bolus dose not effect on final outcome and the rate of patients' death. Also it was observed that the frequency of death among patients with 2-3 clogged vein was high but not meaningful which higher death rate in case group is associated with number of clogged artery. In Steg et al. investigation there was no obvious difference of death rate between heparin receiving and $\mathrm{B}$ vali rodin group. ${ }^{19}$ Montalscat et al, observed that enoxaparin has no difference in death rate and operation success rate in comparison to heparin. ${ }^{20}$ In Stone et al, study, the reported rate of death for heparin group was $3.1 \%$ which was similar to our study, whereas in Bonello et al. study the rate of death for heparin group was lower and reported about $1.1 \%{ }^{17,18}$ Zijlstra et al, observed that heparin prescription group in comparison with no heparin prescription group had lower 30-day death rate $(1.6 \%$ versus $3.4 \%) .{ }^{14}$ Chung et al, showed that in STEMI patients, early heparin treatment in emergency improve coronary patency. ${ }^{16}$ The difference between the findings of this study and other studies can be related to difference in the sample size, risk factors, angiographic characteristics and the time of reaching patients of pain start time to hospital and receiving treatment. For example in this study, heparin receiving patients had more coronary artery that completely affects the treatment and clinical outcomes of patients.

\section{CONCLUSION}

This study showed that, generally, doing primary PCI in STEMI patients has obvious improvement in blood flow of clogged vein and TIMI flow without receiving heparin. Receiving Heparin in these patients with increasing the improvement of clogged vein may lead to better LVEF improvement and finally a better function of left ventricle. Using bolus heparin is not be with high risk of bleeding and had no effect on the 30-day mortality rate of patients.

\section{ACKNOWLEDGEMENTS}

The results of this study supported by Ardabil University of Medical Science and author would like to thank all patients participated in the study and Hospital staff.

Funding: No funding sources

Conflict of interest: None declared

Ethical approval: The study was approved by the Institutional Ethics Committee

\section{REFERENCES}

1. Mozaffarian D, Benjamin EJ, Go AS, Arnett DK, Blaha MJ, Cushman M, et al. Heart Disease and Stroke Statistics- 2015 update: a report from the American Heart Association. Circulation. 2015;131:e29-e322.

2. Longo DKD, Jameson L, Fausi A, Hauser S, Loscalzo J. Principles of Harrison's Internal Medicine. $18^{\text {th }}$ Edition; 2012:495.

3. Sotos-Prieto M, Baylin A, Campos H, Qi L, Mattei J. Lifestyle Cardiovascular Risk Score, Genetic Risk Score, and Myocardial Infarction in Hispanic/Latino Adults Living in Costa Rica. J Am Heart Assoc. 2016 Dec 20;5(12):pii:e004067.

4. Danese E, Montagnana M. An historical approach to the diagnostic biomarkers of acute coronary syndrome. Ann Transl Med. 2016 May;4(10):194.

5. Beig JR, Tramboo NA, Kumar K, Yaqoob I, Hafeez I, Rather FA, et al. Components and determinants of therapeutic delay in patients with acute ST-elevation myocardial infarction: A tertiary care hospital-based study. J Saudi Heart Assoc. 2017 Jan;29(1):7-14.

6. Windecker S, Hernández-Antolín RA, Stefanini GG, Wijns W, Zamorano JL. Management of ST-elevation myocardial infarction according to European and American guidelines. EuroIntervention. 2014 Aug;10 Suppl T:T23-31.

7. American College of Emergency Physicians; Society for Cardiovascular Angiography and Interventions, O'Gara PT, Kushner FG, Ascheim DD, Casey DE Jr, et al. ACCF/AHA guideline for the management of ST-elevation myocardial infarction: a report of the American College of Cardiology Foundation/American Heart Association Task Force 
on Practice Guidelines. J Am Coll Cardiol. 2013 Jan 29;61(4):e78-140.

8. Guillermin A, Yan DJ, Perrier A, Marti C. Safety and efficacy of tenecteplase versus alteplase in acute coronary syndrome: a systematic review and metaanalysis of randomized trials. Arch Med Sci. 2016 Dec $1 ; 12(6): 1181-7$.

9. Briguori C, Visconti G, Focaccio A, Donahue M, Golia B, Selvetella L, et al. Novel approaches for preventing or limiting events (Naples) III trial: randomized comparison of bivalirudin versus unfractionated heparin in patients at increased risk of bleeding undergoing transfemoral elective coronary stenting. JACC Cardiovasc Interv. 2015 Mar;8(3):414-23.

10. Miyachi H, Takagi A, Miyauchi K, Yamasaki M, Tanaka H, Yoshikawa M, et al. Current characteristics and management of ST elevation and non-ST elevation myocardial infarction in the Tokyo metropolitan area: from the Tokyo CCU network registered cohort. Heart Vessels. 2016 Nov;31(11):1740-51.

11. Cho JS, Her SH, Baek JY, Park MW, Kim HD, Jeong $\mathrm{MH}$, et al. Clinical benefit of low molecular weight heparin for ST-segment elevation myocardial infarction patients undergoing primary percutaneous coronary intervention with glycoprotein IIb/IIIa inhibitor. J Korean Med Sci. 2010 Nov;25(11):16018.

12. Ottervanger JP, van't Hof AW, Reiffers S, Hoorntje JC, Suryapranata H, de Boer MJ, et al. Long-term recovery of left ventricular function after primary angioplasty for acute myocardial infarction. Eur Heart J. 2001 May;22(9):785-90.

13. Stolfo D, Cinquetti M, Merlo M, Santangelo S, Barbati $\mathrm{G}$, Alonge $\mathrm{M}$, et al. ST-elevation myocardial infarction with reduced left ventricular ejection fraction: Insights into persisting left ventricular dysfunction. A pPCI-registry analysis. Int J Cardiol. 2016;215:340-5.

14. Zijlstra F, Ernst N, de Boer MJ, Nibbering E, Suryapranata $\mathrm{H}$, Hoorntje JC, et al. Influence of prehospital administration of aspirin and heparin on initial patency of the infarct-related artery in patients with acute ST elevation myocardial infarction. J Am Coll Cardiol. 2002 Jun 5;39(11):1733-7.

15. Verheugt FW, Liem A, Zijlstra F, Marsh RC, Veen G, Bronzwaer JG. High dose bolus heparin as initial therapy before primary angioplasty for acute myocardial infarction: results of the Heparin in Early Patency (HEAP) pilot study. J Am Coll Cardiol. 1998 Feb;31(2):289-93.

16. Chung WY, Han MJ, Cho YS, Kim KI, Chang HJ, Youn TJ, et al. Effects of the early administration of heparin in patients with ST-elevation myocardial infarction treated by primary angioplasty. Circ J. 2007 Jun;71(6):862-7.

17. Stone GW, Witzenbichler B, Guagliumi G, Peruga JZ, Brodie BR, Dudek D, et al. Bivalirudin during primary PCI in acute myocardial infarction. N Engl J Med. 2008 May 22;358(21):2218-30.

18. Bonello L, de Labriolle A, Roy P, Steinberg DH, Pinto Slottow TL, Xue Z, et al. Head-to-head comparison of bivalirudin versus heparin without glycoprotein IIb/IIIa inhibitors in patients with acute myocardial infarction undergoing primary angioplasty. Cardiovasc Revasc Med. 2009 Jul-Sep;10(3):156-61.

19. Steg PG, Van't Hof A, Hamm CW, Clemmensen P, Lapostolle F, Coste P, et al. Bivalirudin started during emergency transport for primary PCI. N Engl J Med. 2013 Dec 5;369(23):2207-17.

20. Montalescot G, Zeymer U, Silvain J, Boulanger B, Cohen M, Goldstein P, et al. Intravenous enoxaparin or unfractionated heparin in primary percutaneous coronary intervention for ST-elevation myocardial infarction: the international randomised open-label ATOLL trial. Lancet. 2011 Aug 20;378(9792):693703.

Cite this article as: Zamani B, Abdollahi A, Mardi A. The effect of heparin prescription before primary PCI on long-term and short-term clinical and para clinical results and the mortality of patients with acute coronary syndrome. Int J Basic Clin Pharmacol 2018;7:748-52. 